\title{
Remote Working and Its Impact on Upper Extremities
}

\author{
Nishita Singh ${ }^{1}$, U. V. Kiran ${ }^{2 *}$, Padmini Pandey ${ }^{3}$, and Vishal Sharma ${ }^{4}$ \\ 'M.Sc. Student, Department of Human Development and Family Studies, School for Home Sciences, Babasaheb Bhimrao \\ Ambedkar University (A Central University), Lucknow - 226025, Uttar Pradesh, India; nishitarks14@gmail.com \\ ${ }^{2}$ Professor, Department of Human Development and Family Studies, School for Home Sciences, Babasaheb Bhimrao \\ Ambedkar University (A Central University), Lucknow - 226025, Uttar Pradesh, India; druvkiran@gmail.com \\ ${ }^{3}$ Research Scholar, Department of Human Development and Family Studies, School for Home Sciences, Babasaheb Bhimrao \\ Ambedkar University (A Central University), Lucknow - 226025, Uttar Pradesh, India; dolly15pandey@gmail.com \\ ${ }^{4}$ Assistant Professor, Institute of Media Studies, Chandigarh University, India
}

\begin{abstract}
Aim: The current investigation was to examine the intensity of pain in upper limbs experienced by the remote workers. Methods: A questionnaire was developed which includes demographic profile sheet, work profile sheet and upper extremity functional index. These tools were used to gather information from the respondents. Google forms links of the questionnaire were mailed to 500 respondents and of which 198 people have responded. This paper focused on the intensity of pain due to prolonged sitting, working from home without any proper workplace. Result: The pain was common among all the ages of respondents but it was little more in the male and also the pain is present in all the professions. Conclusion: The recent pandemic has put more stress on people regarding work from home, online working while sitting, a little of walking. It has impacted people's physical well-being by developing different type of pain in the body.
\end{abstract}

Keywords: Remote Worker, Upper Limbs, Upper Extremity, WRULDs

\section{Introduction}

Work-related musculoskeletal disorders describe a wide range of inflammatory and degenerative diseases and disorders. These conditions result in pain and functional impairment and may affect the neck, shoulders, elbows, forearms, wrists and hands. Work-related neck and upper limb musculoskeletal disorders may be abbreviated as WRULDs and refer to the conditions affecting these regions ${ }^{1}$. The arm and hand is a useful part of the human body. It comprises of three areas, the upper arm, lower arm, and hand. It stretches out from the shoulder joint to the fingers and contains 30 bones. It additionally comprises of numerous nerves, veins (supply routes and veins), and muscles ${ }^{2}$. The upper extremity is depicted by its compactness and ability to deal with, strike, and lead fine motor capacities (control). These attributes are particularly set apart in the hand when performing manual exercises, for example, securing a shirt. Synchronized association occurs between the joints of the upper limb to arrange the mediating portion to perform smooth, useful development at the most workable distance or position required for a specific task. Usefulness of hand work achieves enormous part from the ability to put it in the real circumstance by improvements at the shoulder joint motions, shoulder joint, elbow, and wrist joints ${ }^{3}$. Human upper limbs comprise of a few Degrees of freedom (DOF); fundamentally 3DOF in the shoulder joint, 2DOF in the elbow joint and $2 \mathrm{DOF}$ in the wrist joint. The essential movements of upper limbs can be sorted into eight individual movements shoulder vertical flexion/augmentation, shoulder flat flexion/expansion, shoulder adduction/kidnapping, shoulder interior/outer revolution, elbow flexion/augmentation, lower arm supination/ pronation, wrist flexion/expansion, and wrist ulnar/outspread deviation. The everyday upper limbs movements are the mix of these fundamental movements. Human upper limbs are actuated by numerous sorts of muscles ${ }^{4}$.

The human hand is a staggering resource for identifying and working in the environment, similarly as amazingly complex strategies for physical and social participation. It allows the general population to accomplish refined turns of events, from ability to precision undertakings ${ }^{5}$. In current situation, where time is money and health is wealth, we have lots of work and dealing with our wellbeing too. We frequently overlook the cautions of our own body like ache, delicacy, solidness, shivering, deadness and spasm in the hand and

${ }^{*}$ Author for correspondence 
arm while sitting for extended periods of time and work area occupations. The issues identifying with upper limbs are not a genuine medical problem, on the off chance that we have great working arrangements in workplaces and work from home circumstances. These issues raise when we disregard the alerts of our body and proceed with long working hours in horrible conditions while the shivering and hurt are not kidding upper limbs issue which can't be overlooked any more. Hence the present study is taken up to assess the pain in upper limbs across gender and profession.

\section{Materials and Methods}

\subsection{Selection of Subjects}

Google forms link was mailed to 500 respondents, out of which 198 respondents have replied. The respondents were divided into gender and profession. The respondents were separated based on student, teacher and IT Professional.

\subsection{Data Collection}

The survey was conducted during 15 March - 30 April in 2021. General information sheet was developed which collected data on age, gender, profession, marital status and education level. Work profile sheet was developed to procure information within which no. of working hours, work shifts; job experience, online class hours etc. were included. The Upper Extremity Functional Index (UEFI) was used which is a 5-point scale assessing level of difficulty in performing activities of daily living using upper extremities.

\subsection{Statistical Analysis}

The data was analyzed with the help of the IBM SPSS Statistics Version 20. The degree of upper limb pain was determined with the help of frequency, percentage, mean, standard deviation, and significance was tested using ANOVA.

\section{Results and Discussion}

Results of the study determined that the remote working has increased musculoskeletal pain in people.

Table 1. Distribution of Respondents According to Gender

\begin{tabular}{|l|l|l|}
\hline Gender & Frequency $(\mathbf{N}=198)$ & Percentage (\%) \\
\hline Male & 81 & 40.9 \\
\hline Female & 117 & 59.1 \\
\hline Total & 198 & 100.0 \\
\hline
\end{tabular}

Results in the above table describe the distribution of respondents on the basis of their gender. It shows that $40.9 \%$ of the respondents were male and $59.1 \%$ of the respondents were female. The reason may be that females are mostly involved in remote working since they need to work in home like cleaning, sweeping, cooking etc. Therefore, more of the females are involved in remote working.

Table 2. Distribution of Respondents According to Professional Status

\begin{tabular}{|l|c|c|}
\hline Professional Status & Frequency $(\mathbf{N = 1 9 8 )}$ & Percentage (\%) \\
\hline Student & 127 & 64.1 \\
\hline Teacher & 20 & 10.1 \\
\hline IT Professional & 51 & 25.8 \\
\hline Total & 198 & 100.0 \\
\hline
\end{tabular}

Results in the above table describe the distribution of respondents on the basis of their professional status. It shows that $64.1 \%$ of the respondents were students, $25.8 \%$ of the respondents were IT Professionals and $10.1 \%$ of the respondents were teachers. The reason could be that student are involved more in online classes. Teachers and IT professionals may also have to go to their workplace for the work.

Table 3. Distribution of Professionals According to Number of Working Hours

\begin{tabular}{|l|c|c|c|c|}
\hline $\begin{array}{l}\text { Age of the } \\
\text { respondents }\end{array}$ & $\mathbf{0 - 4}$ hrs. & $\mathbf{4 - 8}$ hrs. & $\mathbf{8 - 1 2}$ hrs. & $\begin{array}{c}\mathbf{1 2} \text { hrs and } \\
\text { above }\end{array}$ \\
\hline $\mathbf{1 8 - 2 4}$ & $1(8.3)$ & $4(33.3)$ & $6(50.0)$ & $1(8.3)$ \\
\hline $\mathbf{2 5 - 3 4}$ & $1(5.3)$ & $6(31.6)$ & $12(63.2)$ & $0(0)$ \\
\hline $\mathbf{3 5 - 4 4}$ & $1(5.6)$ & $4(22.2)$ & $12(66.7)$ & $1(5.6)$ \\
\hline $\mathbf{4 5 - 5 4}$ & $1(7.7)$ & $9(27.3)$ & $3(23.1)$ & $0(0)$ \\
\hline $\begin{array}{l}\mathbf{5 4} \text { and } \\
\text { above }\end{array}$ & $0(0)$ & $10(71.4)$ & $4(28.6)$ & $0(0)$ \\
\hline
\end{tabular}

As it is evident from the table that majority of people of young age group (18-24, 25-34 and 35-44) work for 8 to 12 hours as compared to the middle age (45-54, 54 and above) who work for 4 to 8 hours online. The reason may be that youth are enthusiastic to use new technologies or apps this helps them to save time whereas for older age groups people they love to work manually instead of online.

Table 4. Distribution of Respondents According to Number of Hours Online Class Attended

\begin{tabular}{|l|c|c|c|c|}
\hline $\begin{array}{l}\text { Age of the } \\
\text { respondents }\end{array}$ & $\mathbf{0 - 2}$ hrs. & $\mathbf{2 - 4}$ hrs. & $\mathbf{4 - 6}$ hrs. & $\begin{array}{c}\mathbf{6} \text { hrs. and } \\
\text { above }\end{array}$ \\
\hline $18-24$ & $22(23.7)$ & $37(39.8)$ & $26(28)$ & $8(8.6)$ \\
\hline $25-34$ & $11(37.9)$ & $9(31.0)$ & $5(17.2)$ & $4(13.8)$ \\
\hline
\end{tabular}


From the table above it is seen that majority (39.8\%) of students are involved for 2-4 hours of online classes whereas $37.9 \%$ are involved for only 2 hours of class. The reason for this may be that students for the age group 18-24 years students may have scheduled classes and also after classes they may be online to study from notes or other online references whereas for the age group of 25-34 that they may be involved in classes for less time and may be doing offline studies.

\section{Table 5. Assessment of Pain in Upper Extremities} across Gender

\begin{tabular}{|l|l|l|}
\hline $\begin{array}{l}\text { Difficulties in upper } \\
\text { extremities }\end{array}$ & Male & Female \\
\hline Unable to perform work & $7(8.6)$ & $26(22.2)$ \\
\hline $\begin{array}{l}\text { Extremely difficult to perform } \\
\text { work }\end{array}$ & $23(28.4)$ & $23(19.7)$ \\
\hline Little difficult to perform work & $51(63.0)$ & $68(58.1)$ \\
\hline
\end{tabular}

Chi-Square $=7.056^{*} ; \mathrm{p}$-value $=.029$ (Figures in the parenthesis indicate percentage)

It is evident from the table 5 above those significant differences were observed across gender with the $\mathrm{X}^{2}$ value of 7.056. It can be seen from the data that majority of respondents $(28.4 \%)$ in males have expressed that it is extremely difficult to perform work, followed by $22.2 \%$ females expressed their inability to perform work. Upper extremities pain is more in females as they need to do their office work as well as the household work like cleaning, sweeping, cooking etc. They also need to look after their aged parents and children therefore; females expressed more pain in upper extremities.

Other researchers have also shown that there is the presence of gender differences in the upper extremity musculoskeletal complaints among the working populations as well as within several occupational classes, with women reporting higher numbers of symptoms. Gender differences in health presumably can be regarded as a multicausal phenomenon.

Table 6. Assessment of Pain in Upper Extremities across Profession

\begin{tabular}{|l|c|c|c|}
\hline $\begin{array}{l}\text { Difficulties in } \\
\text { upper extremities }\end{array}$ & Students & Teachers & $\begin{array}{c}\text { IT } \\
\text { Professionals }\end{array}$ \\
\hline $\begin{array}{l}\text { Unable to perform } \\
\text { work }\end{array}$ & $28(22.0)$ & $0(0.0)$ & $5(9.8)$ \\
\hline $\begin{array}{l}\text { Extremely difficult } \\
\text { to perform work }\end{array}$ & $24(18.9)$ & $5(25.0)$ & $17(33.3)$ \\
\hline $\begin{array}{l}\text { Little difficult to } \\
\text { perform work }\end{array}$ & $75(59.1)$ & $15(75.0)$ & $29(56.9)$ \\
\hline
\end{tabular}

Chi-Square $=11.125^{*} ; \mathrm{p}$-value $=.025$ (Figures in the parenthesis indicate percentage)
The data presented in the table 6 above shows that significant differences were observed across profession with the $\mathrm{X}^{2}$ value of 11.125 . It is evident from the data that majority (33.3\%) IT professionals have expressed that is extremely difficult to perform work, followed by $22.0 \%$ students who expressed that is extremely difficult to perform work. From table 3 and table 4 it is evident that students and IT professionals work online for extended hours leading to extreme level of pain. This pain could be due to long hours of sitting down in improper posture, continuously working on laptop and also involved in other online activities like games, net surfing, etc.

Other researches have shown that ergonomics and safe practices have to be established to reduce work related vulnerabilities to increase overall wellbeing of workers.

\section{Conclusion}

The UEFI measures function related to upper extremity injuries and disorders. The relationships between the upper limb motions and the activity levels of main muscles concerning the daily upper-limb motions were analyzed. In present scenario when work from home is very common the awkward position of working, sitting for long time in same position has contributed more in upper limbs disorders. Here it can be seen that females are more affected by the upper limbs problems and regarding profession students are the most affected. The gender differences in symptom severity can be explained by the risk factors at work and at home whereas students with upper extremities symptoms were more likely to be affected due longer time of sitting in the same position while using computers or studying.

\section{References}

1. Buckle PW, Devereux JJ (2002) The nature of work-related neck and upper limb musculoskeletal disorders. https://doi. org/10.1016/S0003-6870(02)00014-5

2. Forro SD, Munjal A, Lowe JB (2020) Anatomy, Shoulder and Upper Limb, Arm Structure and Function

3. https://teachmeorthopedics.info/upper-limb/

4. Gopura RARC, Kiguchi K, Horikawa E (2010) A Study on Human upper limb Muscles Activities during Upper-Limb Motions

5. Cordella F, Ciancio AL, Sacchetti R, et al., (2016) Literature Review on Needs of Upper Limb Prosthesis Users. https:// doi.10.389/fnins.2016.00209

6. Zwart BCH, Frings- Dresen MHW, Kilbom A (2001) Gender differences in upper extremity musculoskeletal complaints in the working population International Archives of Occupational and Environmental Health. February 2001

7. https://www.rehab.msu.edu/_files/_docs/upper_extremity.pdf

8. Devi K, Kiran UV (2015) Work related musculoskeletal disorders among in unorganized sector Int. j. tech. res. appl. e-ISSN: $2320-8163$ 